\title{
O fenômeno da permanência de artefatos comunicacionais efêmeros do universo da cerveja sob a ótica do design emocional
} The phenomenon of the permanence of ephemeral communication artifacts of the beer universe from the point of view of the emotional design

\author{
Maria Beatriz Ardinghi \& Cristiane Aun Bertoldi
}

design emocional, otimização do produto, artefatos comunicacionais da cerveja

\begin{abstract}
Este trabalho aborda as práticas e significados associados a se manter, reutilizar e ressignificar artefatos comunicacionais efêmeros relacionados ao universo da cerveja compreendendo garrafas, rótulos, tampinhas, latas e "bolachas" com conteúdos promocionais. Pelo fato da cerveja se tratar de um produto que é consumido, poderíamos supor que, após o conteúdo ser bebido, a embalagem encerraria as funções para as quais foi desenhada, restando-lhe sua destinação para o descarte e eventual reciclagem. Nota-se um fenômeno de permanência desses artefatos nos ambientes domésticos, onde garrafas e bolachas decoram paredes e estantes, latas transformam-se em vasos, tampinhas preenchem grandes recipientes de vidro. Reutilizados e ressignificados, esses artefatos ganham uma "segunda vida". Interessa-nos compreender os fatores relacionados a esse fenômeno, sob a ótica do design emocional.
\end{abstract}

emotional design, product optimization, communicational beer artifacts

This work discusses the practices and meanings associated with maintaining, reusing and re-signifying ephemeral communicational artifacts related to the beer universe, including bottles, labels, caps, cans and beer mats with promotional contents. Because the beer is a product that is consumed, we could assume that, after the contents have been drunk, the packaging is destined for disposal and eventual recycling. But, instead, a phenomenon of permanence of these artifacts is observed in domestic environments where bottles and beer mats decorate walls and shelves, cans become plant pots, caps fill large glass containers. Reused and redefined, these artifacts gain a "second life". We are interested in understanding the factors related to this phenomenon, from the point of view of emotional design.

\section{Introdução}

Este estudo faz parte de uma pesquisa de doutorado em design que investiga de modo mais abrangente o fenômeno aqui intitulado a "segunda vida dos objetos", a partir de autores do campo do design emocional contrapondo com o conceito de otimização da vida de produtos de Manzini e Vezzoli (2011).

A expressão "segunda vida do objeto" intenciona caracterizar uma situação em que, encerrada a finalidade para a qual foi adquirido, um determinado objeto é mantido, assumindo novas funções e significados, ainda que sofra certa transformação em sua configuração original.

Para este estudo, selecionou-se uma categoria de objetos que emergiu da pesquisa e que estava relacionada ao universo da cerveja, tais como: embalagens, produtos informacionais ou promocionais (garrafas, latas, rótulos, tampinhas, bolachas), oriundos de cervejas industrializadas e artesanais, que foram transformados em objetos simbólicos e afetivos.

Diante deste fato, este trabalho se posicionou na interseção entre três áreas de estudo e atuação do design: Design de Embalagens, Design da Informação e Design Emocional.

Para melhor compreensão, faz-se primeiramente uma breve conceituação das disciplinas para, a seguir, localizar o objeto de estudo, apresentar o método utilizado na pesquisa bem como seus achados.

Anais do $9 \% \mathrm{CIDI}$ e 9 CONGIC

Luciane Maria Fadel, Carla Spinillo, Anderson Horta,

Cristina Portugal (orgs.)

Sociedade Brasileira de Design da Informação - SBDI

Belo Horizonte | Brasil | 2019

ISBN 978-85-212-1728-2
Proceedings of the 9th CIDI and 9th CONGIC

Luciane Maria Fadel, Carla Spinillo, Anderson Horta, Cristina Portugal (orgs.)

Sociedade Brasileira de Design da Informação - SBDI

Belo Horizonte | Brazil | 2019

ISBN 978-85-212-1728-2 


\section{Design da Informação}

Em texto de 1999, Robert Horn definiu o design da informação como 'a arte a ciência de preparar a informação para ser utilizada com eficiência e eficácia pelas pessoas ${ }^{1}$.' (Horn, 1999, p. 15; tradução livre), cujos objetivos primários seriam principalmente as aplicações nas áreas de documentações, nas interface humano-computador e na sinalização, tanto de espaços físicos (urban spaces) quanto virtuais. Segundo o autor, os valores que distinguiriam o design da informação de outros tipos de design seriam a eficiência e a efetividade em seu propósito comunicativo.

Duas décadas depois, Portugal (2010, p. 2) aponta que o termo se alargou e o design da informação 'vai se estabelecendo como um campo que conjuga determinados conhecimentos, traduzindo-se em uma disciplina cujo objetivo é organizar e apresentar dados, transformandoos em informação válida e significativa'. Abrange não somente aspectos funcionais, mas também os componentes emocionais envolvidos nos processos cognitivos de apreensão da informação, em que designers atuam como "tradutores ou interpretes" de uma determinada informação, equacionando aspectos sintáticos, semânticos e pragmáticos dos sistemas de comunicação analógico e digitais, através da contextualização, planejamento, produção e interface gráfica da informação, junto ao seu público alvo.

Estes sistemas abrangem áreas distintas de atuação dos designers, desde produtos impressos como revistas, embalagens ou comunicações corporativas, às mídias digitais e o design de interação. Envolvem desde informações gráficas como mapas e diagramas, ao environmental design, isto é, sinalização e expografias. O que perpassa áreas de atuação tão distintas é a habilidade requerida dos designers, em lidar com grande quantidade e diversidade de dados que precisam ser organizados, transformados e apresentados, de modo que faça sentido (meaningfull) e traga valor (valuable) a um determinado grupo de pessoas.

Artefatos que fazem parte do universo das embalagens de cerveja, como rótulos e tampas das garrafas, latas e bolachas podem ser compreendidos como sistemas informacionais uma vez que lidam com a tarefa de informar uma grande quantidade de dados distintos abarcando desde o tipo da cerveja (Pilsen, Lager, Dortmunder, Ale, Stout, entre outras) até exigências legais impostas pelos órgãos reguladores como graduação alcoólica, conteúdo, lote, validade, aviso sobre conteúdos alergênicos, número de registro, entre outras. Ao mesmo tempo, devem atuar em conjunto como pontos de contato da marca com o público, em prol de uma comunicação coesa, significativa e que tenha valor para o consumidor.

Este trabalho foca nas características estéticas e simbólicas destes artefatos informacionais, e não tão somente nos seus aspectos funcionais, aproximando assim a disciplina do Design Emocional.

\section{Design de Embalagens}

Negrão e Camargo (2008, p. 29) definem embalagem como 'um sistema cuja função é técnica e comercial e tem como objetivo acondicionar, proteger (desde o processo de produção até o consumo), informar, identificar, promover e vender um produto'. A proteção implica na integridade do produto, do acondicionamento ao transporte, recebimento e uso do produto pelo consumidor final preservando-o em relação a riscos biológicos, climáticos, físicos e de desfalque. Informar e identificar relacionam-se tanto com o design de informação em seus aspectos funcionais, técnicos e legais, quanto com branding, no que diz respeito à atributos de identidade, personalidade do produto e relacionamento da marca. Promover e vender consistem nas principais preocupações do varejo em relação às embalagens uma vez que, segundo Mestriner (2002) cerca de $90 \%$ dos produtos comercializados no país dependem somente da embalagem como instrumento de venda.

Entretanto, o ciclo de vida das embalagens não se encerra no consumo, mas no descarte. Com relação às embalagens e o meio-ambiente, dados sobre lixo doméstico das últimas

\footnotetext{
1 'Information design is defined as the art and science of preparing information so that it can be used by human beings with efficiency and effectiveness'. (HORN, 1999, p. 15)
} 
décadas reforçam a importância do design voltado para a sustentabilidade: um terço do lixo doméstico no Brasil é composto por embalagens sendo que cerca de $80 \%$ das embalagens são descartadas após usadas apenas uma vez ${ }^{2}$ (produto de monouso); $30 \%$ a $40 \%$ dos resíduos sólidos urbanos são considerados passíveis de reaproveitamento e reciclagem entretanto apenas $13 \%$ são encaminhados para a reciclagem ${ }^{3}$.

Nas últimas décadas, no campo de atuação do design de embalagens, nota-se a crescente preocupação em relação às exigências ambientais legais, a adoção de medidas a favor da estratégia conhecida como 3 R's - redução, reuso, reciclagem, bem como o surgimento de novos materiais como plásticos biodegradáveis e materiais compósitos (Stewart, 2010).

Segundo Manzini e Vezzoli (2011), a necessidade de se integrar requisitos ambientais no desenvolvimento de produtos e serviços, incluindo embalagens, considera os impactos ambientais gerados em cada etapa do ciclo de vida de um produto e envolve diferentes estratégias tais como: minimizar os recursos, escolher recursos e processos de baixo impacto ambiental, estender a vida dos materiais, facilitar a desmontagem e otimizar a vida dos produtos, esta última relacionada com os casos aqui estudados.

Para os autores, otimizar a vida dos produtos refere-se principalmente a: (1) o aumento da durabilidade dos produtos e (2) a intensificação de uso dos produtos. Para produtos de monouso, como embalagens, sugerem aumentar sua vida útil ou mesmo substituí-los por outros produtos reutilizáveis.

Propõem, por outro lado, a dimensão social e econômica da mudança referindo-se aos valores da sociedade atual vinculados à posse dos bens de consumo e defendem um estímulo à mudança em relação a esse paradigma. Convidam à reflexão sobre os próprios padrões de qualidade com os quais julgamos os produtos em nossas vidas, bem como nossa noção de satisfação às necessidades e desejos. Por seu viés emocional, esta discussão se aproxima dos estudos do Design Emocional.

\section{Design Emocional}

O Design Emocional pode ser compreendido como um campo do design interessado em identificar e sistematizar a intenção e os procedimentos de projeto com vistas a despertar ou evitar emoções na experiência de interação das pessoas com os artefatos (Tonetto \& Da Costa, 2011).

Os aspectos envolvidos na relação das pessoas com os objetos tem sido o foco do trabalho de Norman (2008), principalmente na interação com as coisas cotidianas. Segundo o autor, as emoções estão relacionadas a três níveis de processamento cerebral aos quais relaciona três estratégias de design: (1) visceral, (2) comportamental e (3) reflexivo.

O aspecto visceral diz respeito aos atributos físicos do objeto, ao primeiro impacto deste em nós. Por exemplo, a aparência de um objeto que chama a atenção na prateleira da loja. $O$ aspecto comportamental diz respeito ao uso, objetivamente à sua função e à sua eficácia, como é sua usabilidade do ponto de vista funcional, a facilidade e o prazer de operá-lo. Por fim, o aspecto reflexivo do objeto diz respeito ao caráter subjetivo, à relação de significados que atribuímos ao objeto; abrange particularidades culturais e individuais, memória afetiva e outros aspectos intangíveis (Norman, 2008).

Para Jordan (2000), os seres humanos estão sempre em busca de prazer. O mesmo acontece na interação com os objetos, onde as necessidades obedecem a seguinte hierarquia: primeiro em relação à funcionalidade, segundo à usabilidade e, por fim, ao prazer. Para o autor, benefícios práticos, emocionais e hedônicos explicam o prazer com os objetos. Os benefícios práticos aparecem no resultado das tarefas para as quais um produto é utilizado, os emocionais se referem a como este produto afeta o estado emocional de uma pessoa e os hedônicos relacionam-se aos prazeres sensoriais e estéticos promovidos por seu contato.

2 Fonte: Manual para Consumo Sustentável do Ministério do Meio Ambiente, 2005.
${ }^{3}$ Fonte: Ipea, Instituto de Pesquisa Econômica Aplicada, 2017. 
Jordan (2000) sistematizou uma classificação sobre fontes de prazer relacionadas à interação das pessoas com os produtos e separou o prazer em quatro categorias: (1) prazeres fisiológicos, que envolvem sensações corporais e está relacionado ao corpo e aos sentidos onde visão, audição, paladar, tato, olfato e prazer sensual são fontes de prazer; (2) prazeres sociológicos, que dizem respeito às interações sociais e interpessoais; (3) prazeres psicológicos, que tem relação com o self, isto é, referem-se às realizações do "eu" e da "mente" e com os processos cognitivos; (4) prazeres ideológicos correspondem à estimulação intelectual do indivíduo e relaciona-se com os seus valores.

Tonetto e Da Costa (2011) argumentam que o modelo de Jordan (2000) não se destina a compreender o porquê de as pessoas experimentarem prazer. Entretanto, classificar e estruturar os tipos de prazer consiste em uma ferramenta para auxiliar designers a lidar de forma estruturada com o problema e elencar formas de gratificar os usuários na relação com os objetos.

\section{Método}

Como citado, este estudo é um recorte de uma pesquisa de doutorado em andamento, que investiga a atribuição de novas funções e significados por parte dos indivíduos a objetos que cumpriram o papel para o qual foram adquiridos e que, ao invés de serem descartados, são mantidos e ressignificados pelas pessoas. Primeiramente, realizou-se um questionário online com 59 respondentes, a fim de levantar casos que se enquadrassem no fenômeno de atribuição definido pela expressão "segunda vida do objeto" e os fatores que motivam as pessoas a fazê-lo. Foram colhidos relatos sobre 136 objetos de diferentes categorias, de bens duráveis a embalagens. Entre os casos identificados, emergiu a categoria aqui relatada, mencionada por 7 respondentes, dos artefatos informacionais relacionados à cerveja garrafas, rótulos, tampinhas, latas e bolachas.

Um novo questionário online foi formulado, contendo perguntas de múltipla escolha e questões abertas, com o foco na categoria de artefatos mencionada, de onde foram extraídos novos dados. Para este novo questionário participaram 20 respondentes; foram abordados os fatores que motivaram as pessoas a manterem os artefatos, e qual o destino conferido àqueles.

Partindo-se da premissa identificada nos estudos preliminares de que os fatores motivadores são de ordem emocional, foi apresentada uma lista com 36 emoções oriundas dos estudos de Scherer $(2005)^{4}$ no design emocional, a fim de mapear as relações afetivas das pessoas com os artefatos.

Indagou-se sobre o local onde o objeto se encontra - qual ambiente, se exposto ou guardado - de modo a vincular o objeto à presença de outras pessoas no local, família ou amigos. Ao final, pedia-se ao respondente que selecionasse uma das cinco categorias dadas sobre hábitos de consumo de cerveja, que melhor o caracterizasse como consumidor.

A fase subsequente consistiu em entrevistas semiestruturadas, realizadas com aqueles cujas respostas ao questionário indicaram relações de afeto com os objetos, levando em conta as distinções quanto a novos usos conferidos àqueles objetos.

Os dados obtidos por meio dos questionários e entrevistas foram analisados e classificados como detalhado a seguir.

\footnotetext{
${ }^{4}$ A lista de emoções de Scherer (2005), foi elaborada junto ao Geneva Emotion Research Group da Universidade de Genebra a fim de padronizar os termos relacionados aos estudos da emoção; faz parte de um conjunto de instrumentos utilizados para se medir reações emocionais a objetos, eventos e situações. https://www.unige.ch/cisa/emotional-competence/home/
} 


\section{Resultados}

Os respondentes são 9 mulheres e 11 homens, que têm entre 20 e 67 anos e diferentes profissões como chaveiro, restauradora, estudante e engenheiro, entre outras. Moram em companhia de outras pessoas, companheiros, filhos ou colegas de república estudantil, com exceção de um dos respondentes que vive só. No que se refere ao comportamento de consumo em relação à cerveja, 8 pessoas definiram-se como (a) um simples bebedor de cerveja; outras 6 pessoas como (b) um apreciador de cerveja que conhece os estilos e ingredientes típicos; 4 pessoas como (c) um produtor eventual de cerveja artesanal, normalmente com amigos; uma pessoa considera-se (d) um expert em cerveja e um respondente é (e) um profissional que trabalha com cerveja.

Todos têm em comum o fato de não descartarem certas latas, garrafas, rótulos, tampinhas e bolachas de cerveja, conferindo a estes objetos destinações diferentes de suas funções originais, o que classifica o fenômeno como uma nova noção de reuso, uma vez que, tecnicamente, o termo reuso significa 'qualquer operação pela qual a embalagem, que foi concebida e desenhada para executar dentro de seu ciclo de vida um número mínimo de viagens e rotações, é enchida novamente ou reusada para o mesmo propósito para o qual foi concebido' (Stewart, 2010, p. 139).

\section{Motivações}

O questionário apresentou duas questões distintas a fim de classificar possíveis motivações que levam as pessoas a manterem os artefatos. Na primeira questão, pedia-se ao respondente que identificasse a motivação que o levou a guardar um dos objetos citados, a partir de uma lista de possíveis razões que emergiram dos primeiros dados coletados.

Em seguida, por meio de uma questão de múltipla escolha, solicitava-se ao respondente classificar sua motivação de acordo com as 7 categorias levantadas na fase anterior da pesquisa, de acordo com códigos preliminarmente definidos: (1) ESTÉTICO, efeito decorativo; (2) COLEÇÃO; (3) SOUVENIR, lembrança daquele lugar; (4) MEMÓRIA, momento a se eternizar; (5) RARIDADE, pouca gente tem; (6) TROFÉU, conquista pessoal; (7) NARRATIVA, assunto pra muitas histórias.

Os dados foram posteriormente analisados e classificados segundo os aspectos emocionais de Norman (2008) - visceral, comportamental e reflexivo, e os tipos de prazer na interação com os objetos de Jordan (2000) - fisiológico, social, psicológico e ideológico (Tabela 1). 
Tabela 1: Análise dos objetos e as motivações declaradas de acordo com Norman (2008) e Jordan (2000).

\begin{tabular}{|c|c|c|c|c|c|c|c|c|c|c|c|c|c|c|c|c|}
\hline \multirow[b]{2}{*}{$\begin{array}{l}\text { 음 } \\
\text { m. } \\
\text { ơ }\end{array}$} & \multirow[b]{2}{*}{ 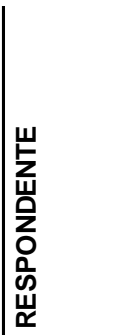 } & \multicolumn{8}{|c|}{ MOTIVAÇÃO PARA GUARDAR } & \multicolumn{3}{|c|}{ Norman (2008) } & \multicolumn{4}{|c|}{ Jordan (2000) } \\
\hline & & $\begin{array}{l}\text { O } \\
\frac{w}{5} \\
\frac{w}{4}\end{array}$ & 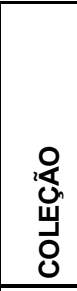 & 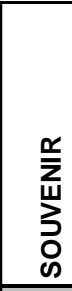 & 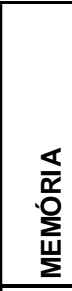 & 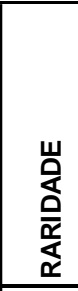 & 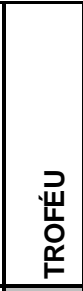 & 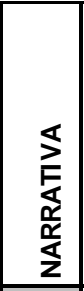 & 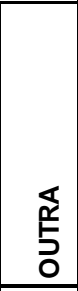 & 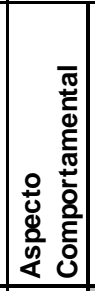 & 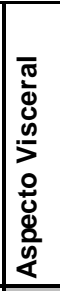 & 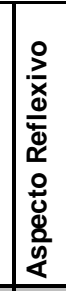 & 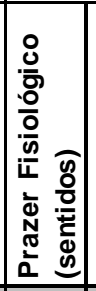 & 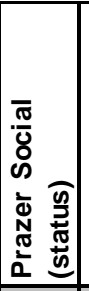 & 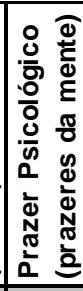 & 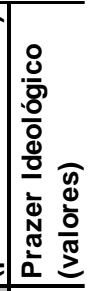 \\
\hline$T$ & A.R. & & & & & & & & & & & & & & & \\
\hline B & A.R. & & & & & & & & & & & & & & & \\
\hline$L$ & A.O.E. & & & & & & & & & & & & & & & \\
\hline $\mathrm{G}$ & A.O.E. & & & & & & & & & & & & & & & \\
\hline $\mathrm{T}$ & \begin{tabular}{|l|} 
A.P. \\
\end{tabular} & & & & & & & & & & & & & & & \\
\hline $\mathrm{G}$ & A.C.S.G & & & & & & & & & & & & & & & \\
\hline $\mathrm{B}$ & A.C.S.G & & & & & & & & & & & & & & & \\
\hline $\mathrm{R}$ & A.C.S.G & & & & & & & & & & & & & & & \\
\hline $\mathrm{G}$ & A.P. & & & & & & & & & & & & & & & \\
\hline $\mathrm{T}$ & A.P. & & & & & & & & & & & & & & & \\
\hline $\mathrm{R}$ & A.P. & & & & & & & & & & & & & & & \\
\hline $\mathrm{L}$ & A.C.G.N & & & & & & & & & & & & & & & \\
\hline $\mathrm{G}$ & A.C.G.N & & & & & & & & & & & & & & & \\
\hline $\mathrm{B}$ & A.C.G.N & & & & & & & & & & & & & & & \\
\hline $\mathrm{R}$ & A.C.G.N & & & & & & & & & & & & & & & \\
\hline$T$ & A.C.G.N & & & & & & & & & & & & & & & \\
\hline $\mathrm{T}$ & \begin{tabular}{|l|} 
C.M. \\
\end{tabular} & & & & & & & & & & & & & & & \\
\hline $\mathrm{G}$ & C.M. & & & & & & & & & & & & & & & \\
\hline $\mathrm{G}$ & F.T. & & & & & & & & & & & & & & & \\
\hline $\mathrm{L}$ & G.M.S. & & & & & & & & & & & & & & & \\
\hline $\mathrm{L}$ & G.G.S. & & & & & & & & & & & & & & & \\
\hline $\mathrm{G}$ & G.G.S. & & & & & & & & & & & & & & & \\
\hline $\mathrm{G}$ & G.P. & & & & & & & & & & & & & & & \\
\hline $\mathrm{L}$ & G.H.C. & & & & & & & & & & & & & & & \\
\hline $\mathrm{G}$ & G.H.C. & & & & & & & & & & & & & & & \\
\hline $\mathrm{B}$ & G.H.C. & & & & & & & & & & & & & & & \\
\hline$T$ & G.H.C. & & & & & & & & & & & & & & & \\
\hline $\mathrm{L}$ & G.R. & & & & & & & & & & & & & & & \\
\hline $\mathrm{G}$ & G.R. & & & & & & & & & & & & & & & \\
\hline $\mathrm{L}$ & J.D.F. & & & & & & & & & & & & & & & \\
\hline$\underline{L}$ & J.G. & & & & & & & & & & & & & & & \\
\hline $\mathrm{G}$ & J.G. & & & & & & & & & & & & & & & \\
\hline $\mathrm{G}$ & J.G. & & & & & & & & & & & & & & & \\
\hline$T$ & J.G. & & & & & & & & & & & & & & & \\
\hline $\mathrm{R}$ & J.G. & & & & & & & & & & & & & & & \\
\hline $\mathrm{G}$ & \begin{tabular}{|l} 
K.L. \\
\end{tabular} & & & & & & & & & & & & & & & \\
\hline $\mathrm{L}$ & K.L. & & & & & & & & & & & & & & & \\
\hline$G$ & M.D. & & & & & & & & & & & & & & & \\
\hline $\mathrm{T}$ & M.D. & & & & & & & & & & & & & & & \\
\hline $\mathrm{R}$ & M.D. & & & & & & & & & & & & & & & \\
\hline $\mathrm{L}$ & P.D.M. & & & & & & & & & & & & & & & \\
\hline $\mathrm{G}$ & P.D.M. & & & & & & & & & & & & & & & \\
\hline $\mathrm{T}$ & P.D.M. & & & & & & & & & & & & & & & \\
\hline$B$ & P.D.M. & & & & & & & & & & & & & & & \\
\hline$L$ & R.C. & & & & & & & & & & & & & & & \\
\hline$R$ & R.C. & & & & & & & & & & & & & & & \\
\hline$B$ & R.C. & & & & & & & & & & & & & & & \\
\hline $\mathrm{G}$ & S.L. & & & & & & & & & & & & & & & \\
\hline $\mathrm{R}$ & S.L. & & & & & & & & & & & & & & & \\
\hline Inci & dência & 27 & 21 & 18 & 14 & 11 & 7 & 6 & 5 & 8 & 36 & 36 & 35 & 14 & 21 & 0 \\
\hline
\end{tabular}

Nota: (L) Lata; (G) Garrafa; (R) Rótulo; (T) Tampinha; (B) Bolacha

Anais do 9 Congresso Internacional de Design da Informação | CIDI 2019

Proceedings of the 9th Information Design International Conference

Anais do $9^{\circ}$ Congresso Nacional de Iniciação Científica em Design da Informação | CONGIC 2019

Proceedings of the $9^{\text {th }}$ Information Design Student Conference 
De acordo com a análise, foi possível notar que o critério de seleção dos artefatos para permanência ou reuso está associado, principalmente, com motivação de ordem estética (27), o que se relaciona aos aspectos viscerais (36) dos artefatos, que proporcionam prazer fisiológico (35) na interação. Ainda que o objeto tenha hoje uma utilidade, uma função prática, seu caráter comportamental (8) é menos relevante do que sua função estética.

Em segundo lugar, aparecem as motivações vinculados às memórias, que englobam tanto as lembranças de lugares, os souvenirs (18) quanto as experiências memoráveis de consumo (14), todas relacionadas com aspectos reflexivos dos objetos, vinculados aos prazeres fisiológico e social. Em seguida estão as coleções, de caráter fortemente decorativo, mas essencialmente simbólico, portanto, reflexivo. Em alguns casos, quando expostas, relacionamse com o prazer social; quando são coleções guardadas longe da observação alheia, estão vinculadas apenas ao prazer psicológico pelo colecionismo, em que são auto impostos desafios para conquistar novos exemplares, ampliando a variedade e, por vezes, a raridade.

Interessante notar o alto índice de ocorrência dos termos raridade e troféu. Sobre o primeiro, podemos fazer um paralelo com o que Baudrillard chama de objeto-único (2004, p.99), exemplo máximo do simbolismo do objeto uma vez que a singularidade substitui a série e a quantidade. Em ambos os casos, os aspectos reflexivos do fenômeno estão fortemente relacionados às atribuições de status (prazer social), e às expressões do self (prazer psicológico) em um processo simultâneo de diferenciação e integração na comparação com os outros, segundo Csikszentmihalyi e Rochberg (1981, p. 38).

Não foi identificada nenhuma motivação associada ao prazer ideológico.

\section{Emoções}

A partir do questionário, foi solicitado ao respondente que selecionasse aquelas emoções associadas ao objeto citado, baseadas na lista de emoções de Scherer (2005) dividida em 19 termos de conotação positiva (Gráfico 1) e 17, negativa (Gráfico 2).

Gráficos 1: Emoções positivas associadas aos artefatos, por categoria de motivação.

\section{EMOÇÕES POSITIVAS (212)}

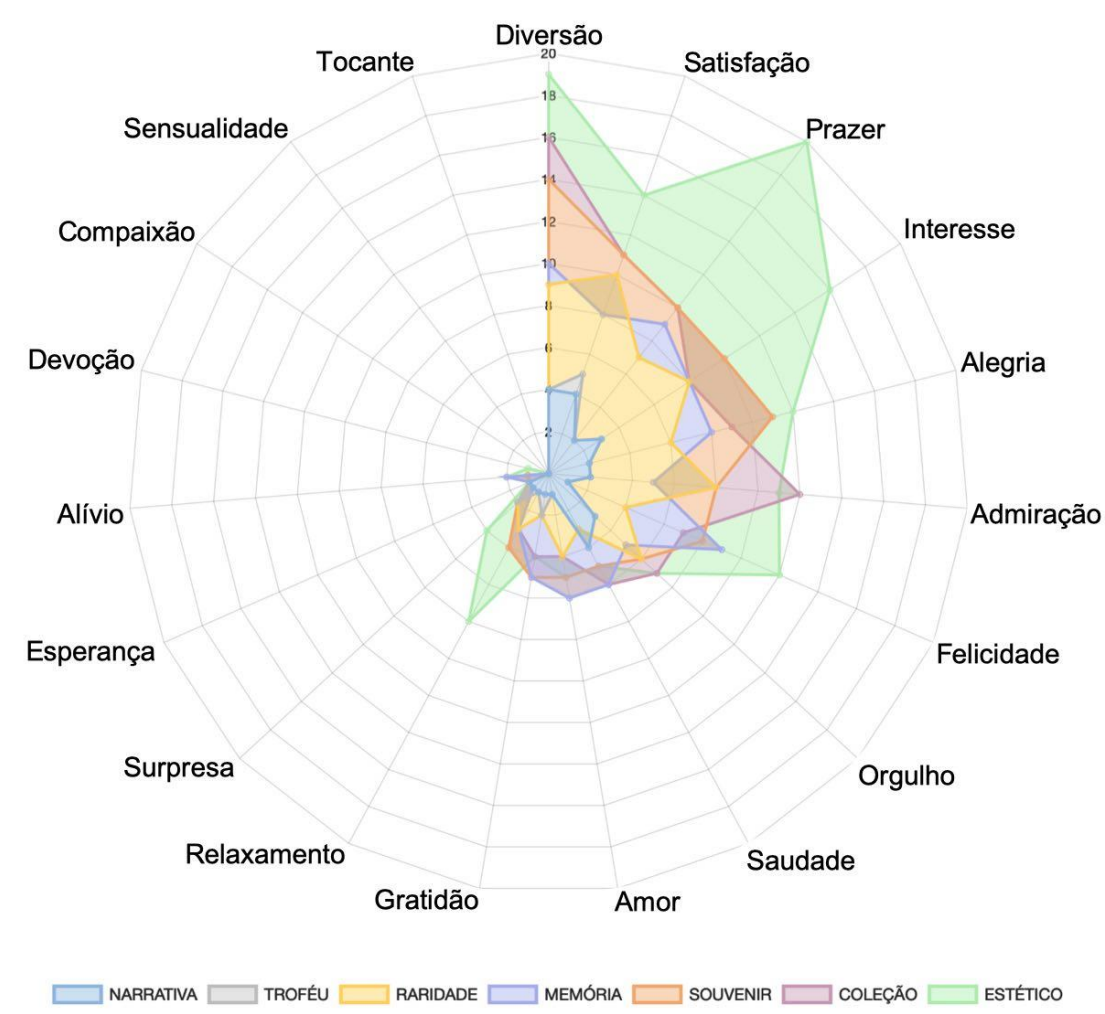


Gráficos 2: Emoções negativas associadas aos artefatos, por categoria de motivação.

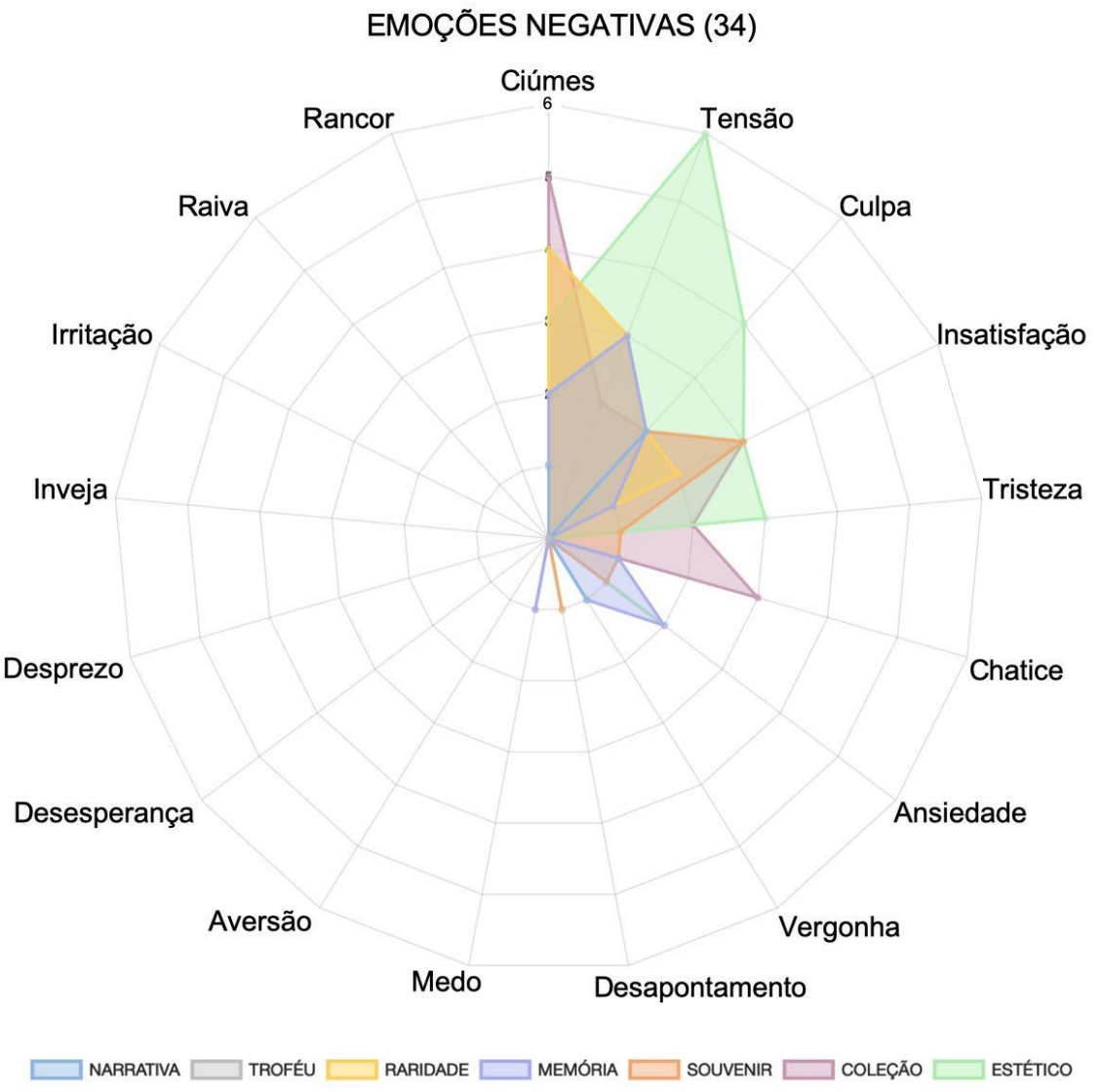

Os Gráficos 1 e 2 mostram respectivamente a incidência das emoções positivas (212 relatos) e negativas (34 relatos), distribuídas pelas categorias de motivação.

A primeira evidência é que os objetos estão mais fortemente associados às emoções positivas, mas não somente. Apesar dos termos positivos terem sido elencados significativamente mais vezes (212), as emoções negativas também estão presentes (34). Isto indica que, mesmo que o objeto desperte ou tenha despertado no momento de consumo uma emoção negativa, ele não foi descartado, tendo sido mantido ainda que em conflito. Segundo Lazarus (1991), nós só sentimos emoção em relação àquilo com o que nos importamos, que 'toca nossos valores', mesmo em relação às emoções negativas.

Aqui encontram-se por exemplo, as coleções que causam ciúme nos parceiros, garrafas de vidro que, dispostas sem proteção na prateleira podem se quebrar, entre outros relatos associados às emoções negativas como ciúmes, tensão ou medo.

As emoções positivas mais citadas foram diversão, satisfação e prazer; é importante pontuar que algumas estão mais relacionadas aos momentos de consumo das bebidas do que à permanência e destinação posterior das embalagens. O que ocorre é que essas emoções acabam materializadas nas embalagens que passam à qualidade de objetos memoráveis e são valorizados pelas experiências de que tomaram parte (Damazio, 2005), onde o gatilho de memória é, por vezes, a própria marca ou algum elemento visual do rótulo, como uma paisagem retratada ou uma localidade. 


\section{Segunda-vida dos objetos}

Foram observadas diferentes funções ${ }^{5}$ atribuídas aos objetos em sua nova fase de vida.

Dividimos as ocorrências em seis grupos, nomeados de acordo com sua nova função preponderante, a partir de palavras extraídas dos depoimentos: Coleção, Medidor, Enfeite, Utilitário, Revestimento e Enfeite Útil.

\section{Coleção}

Existem dois conceitos associados à noção de coleção, o primeiro é o encanto pela diversidade dos objetos no conjunto formado, e o segundo, o apreço pelo singular, onde cada tipo é único.

Para Baudrillard (2004), quando se trata do objeto de coleção, chamado pelo autor de objeto-paixão, o prazer vem prioritariamente da posse, tanto pela singularidade absoluta de cada elemento, o que equivale com a noção de ser do próprio indivíduo perante o mundo, quanto com a possibilidade da série e da substituição indefinida do jogo, 'quintessência qualitativa, manipulação quantitativa' (Baudrillard, 2004, p.96).

De acordo com Jordan (2000), o prazer se dá pela interação; neste caso a arrumação e a catalogação associam-se com o prazer psicológico, enquanto que a fruição estética diz respeito ao prazer fisiológico.

Baudrillard (2004, p.96) diferencia os 'colecionadores' dos 'amadores de objetos' pelo fato de que estes 'amam os objetos por seu encanto diverso e singular' enquanto os primeiros, 'em função de sua ordem em uma série'. Portanto, nenhum caso encontrado na pesquisa enquadra-se na classificação de coleção criada por um colecionador e sim por amadores de objetos. Mesmo assim foi mantido como título desta categoria temática o termo coleção, porque os objetos foram assim descritos pelos entrevistados, e o interesse deste estudo está na emoção emanada por tais objetos.

As coleções foram encontradas em duas diferentes configurações e ambas são promotoras de prazer psicológico na interação com o objeto-paixão.

A primeira (Figura 1) apresenta-se exposta, organizada e distribuída em prateleiras, móveis e paredes, destinadas a acomodar garrafas, bolachas e latas que, além de exibirem o conjunto, proporcionam a observação do singular, de cada rótulo ou tipo. Destacam-se emoções como satisfação, admiração e orgulho relacionadas às coleções em si, por seu tamanho e apresentação, bem como referentes a alguns exemplares, por sua raridade, origem ou fama, diretamente relacionados ao prazer social.

Além disso, estes objetos adquiriram uma nova função comunicacional: promovem narrativas sobre estilos de cerveja, ingredientes e demais detalhes específicos, interessantes para os amantes do assunto diante de seus rótulos.

${ }^{5} \mathrm{O}$ termo função aqui utilizado tem uma conotação mais ampla do que a simples utilidade do objeto. Baseado em Löbach (1981), entende-se que os artefatos podem exercer função prática, função estética ou função simbólica na vida do sujeito.

Anais do 9o Congresso Internacional de Design da Informação | CIDI 2019

Proceedings of the 9th Information Design International Conference

Anais do $9^{\circ}$ Congresso Nacional de Iniciação Científica em Design da Informação | CONGIC 2019

Proceedings of the $9^{\text {th }}$ Information Design Student Conference 
Figura 1: Coleções de garrafas, latas e bolachas arrumadas e expostas preenchem paredes.
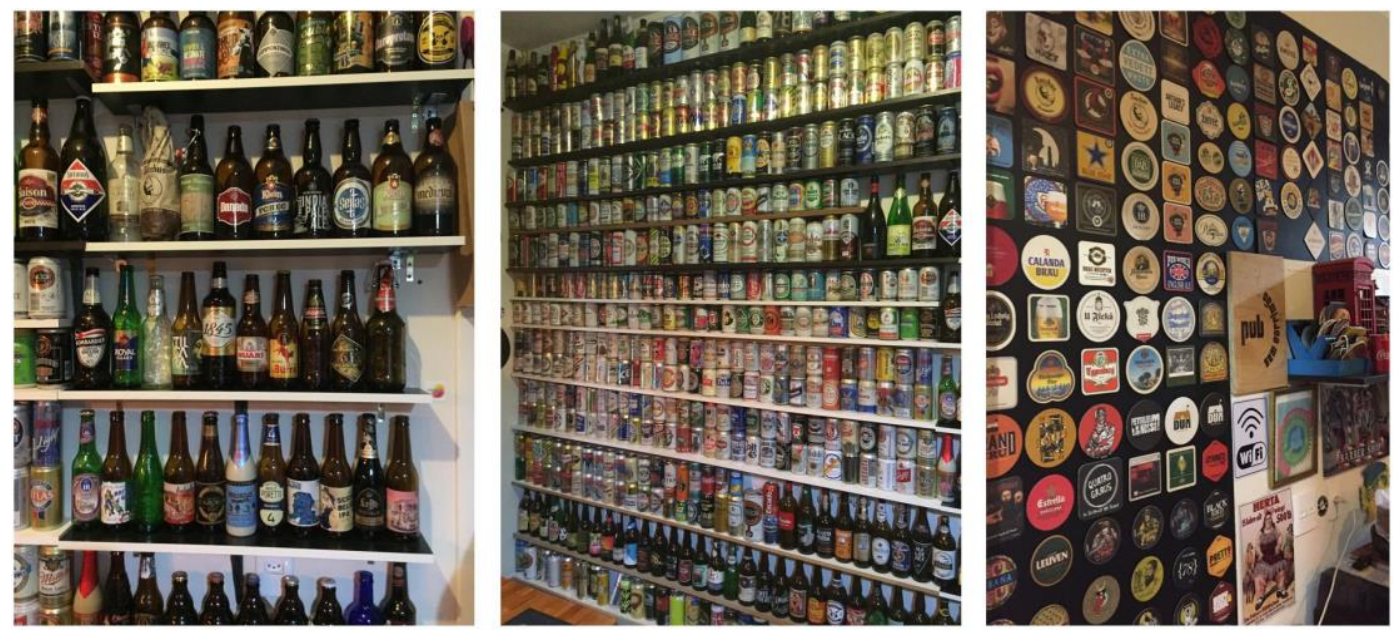

A segunda configuração da coleção não se exibe; contrariamente, estes objetos encontram-se guardados, longe do acesso das pessoas, tanto de forma catalogada em pastas-arquivos preenchidas com rótulos e tampas, quanto de maneira desorganizada, aguardando uma melhor disposição (Figura 2).

Figura 2: Pasta-arquivo com coleções de rótulos e tampas e coleção de bolachas guardadas em armários, longe do alcance da visão (usado com a permissão de A.P. e P.A.).
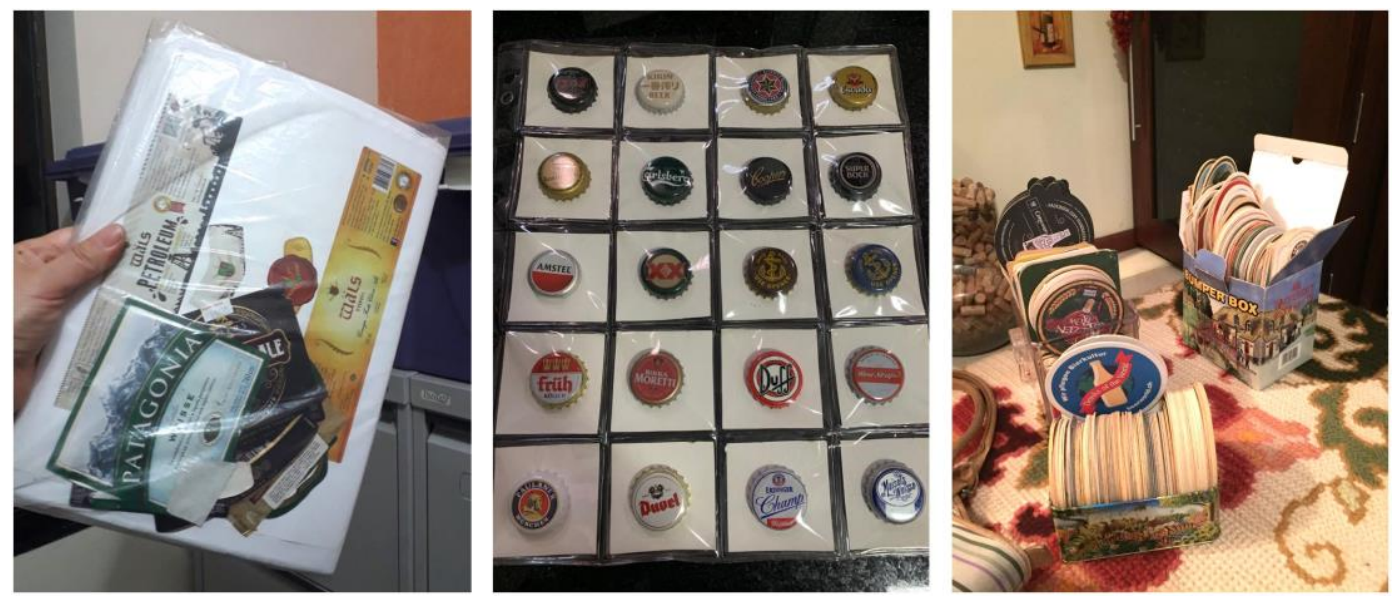

Expostos ou arquivados, rótulos, tampinhas, bolachas, garrafas e latas passam por um processo de arranjo, classificação e manipulação que corresponde ao 'modo mais rudimentar de domínio do mundo exterior' (Baudrillard, 2004, p. 95).

\section{Medidor}

Alguns objetos se apresentam como medidores, associados à noção de quantidade e conquista, fenômeno vinculado à posse do objeto-paixão de Baudrillard (2004) e ao prazer psicológico de Jordan (2000). Isto pode ser observado nos vasilhames transparentes (Figura 3) que atuam como medidores onde depositam-se tampas, nos quais não interessa a singularidade, apenas a quantidade. Nestes casos, relacionados com os aspectos reflexivos de Norman (2004), a função simbólica é predominante e a busca pela completude é um desafio a ser atingido. 
Figura 3: Vasilhames transparentes atuam como medidores de quantidade de tampas (usado com a permissão de A.R.)
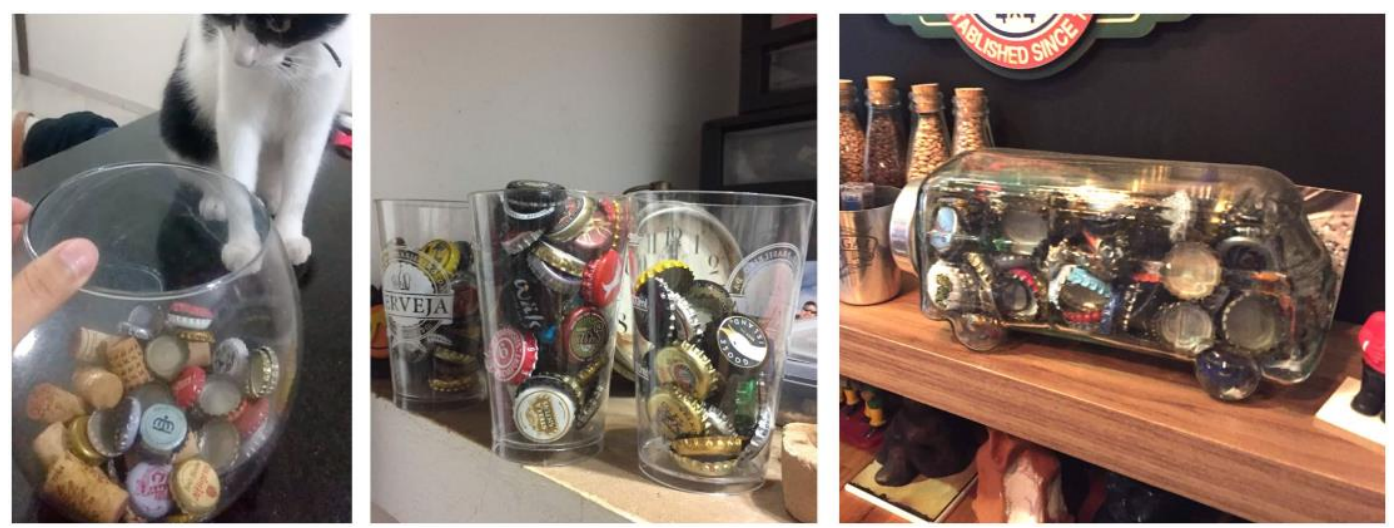

\section{Enfeite}

Aqui estão os objetos cuja nova função é, tão somente decorar, portanto estética. Atributos estéticos relevantes presentes nos objetos promovem o fenômeno transformando-os em "enfeites", de modo que, por exemplo, uma série de bolachas selecionadas transforma-se em quadro e a garrafa solitária de cerveja enfeita a prateleira do quarto, escolhida por se assemelhar a uma garrafa de champagne por seu formato e sistema de fechamento (Fig. 4). Aspectos viscerais são predominantes nestes objetos e promovem prazer fisiológico na contemplação.

Figura 4: Quadro de vidro com bolachas e garrafa de cerveja estilo champagne enfeitam os ambientes.
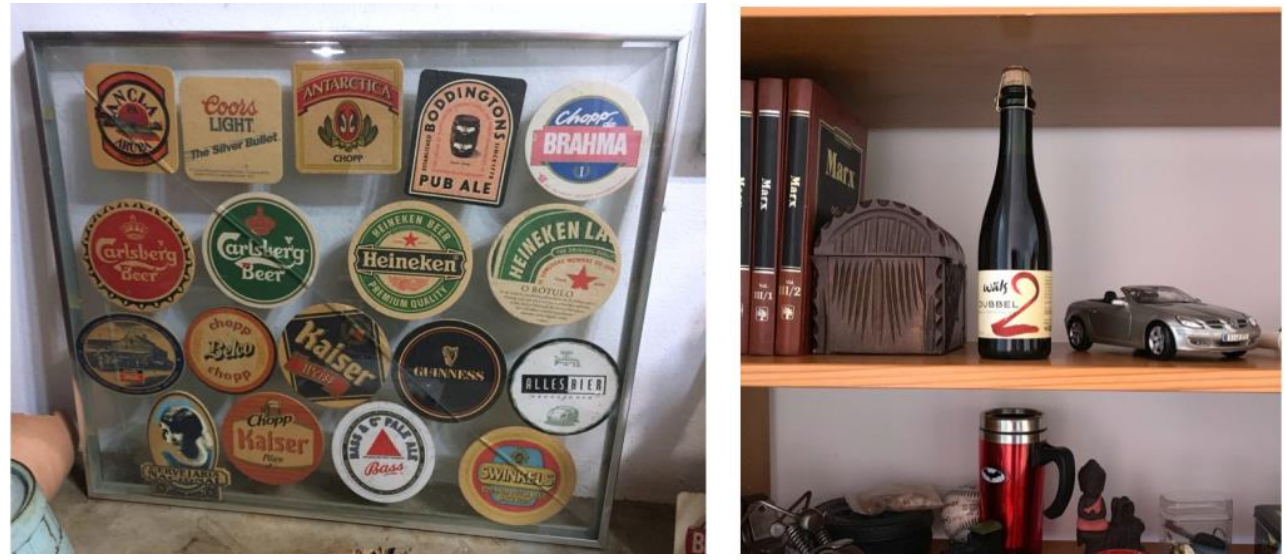

\section{Utilitário}

Nesta categoria estão os objetos cuja nova função tem um caráter prático de funcionalidade ainda que alguns aspectos estéticos contribuam para sua escolha. Este é o caso, por exemplo, de uma lata cuja tampa superior foi removida para ser usada como porta-lápis, e das garrafas long neck de cerveja cortadas e transformadas em copos. O fato de serem de vidro transparente e possuírem um formato "cinturado" foi decisivo na escolha, em detrimento de outras garrafas de vidro verde e cilíndricas, por exemplo (Figura 5).

Neste caso identificamos uma relação de prazer fisiológico (Jordan, 2000) mesmo quando a motivação foi de ordem prática, utilitária, relacionada com aspectos comportamentais dos produtos (Norman, 2004). 
Figura 5: Copos feitos a partir de garrafas long neck cortadas e lata de cerveja transformada em porta-lápis (usado com a permissão de G.P. e R.C.)
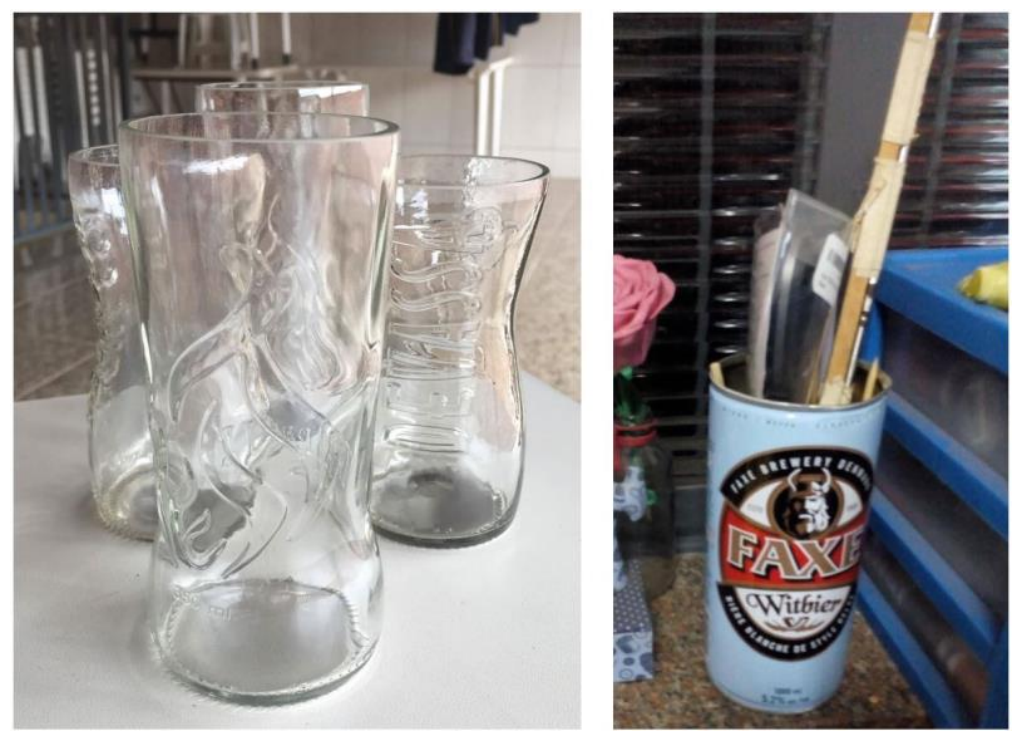

\section{Revestimento}

Nesta categoria, o valor se dá pelo conjunto, prazer fisiológico de apreciação do resultado estético da "colagem" e da temática conferida ao ambiente onde estes objetos, agora revestidos, se encontram. O atributo estético reside na profusão de rótulos e tampas, enquanto sua função prática é conferir nova visualidade a objetos existentes, no caso um tampo de mesa, um cooler e uma velha geladeira (Fig. 6). Soma-se a isso o sentimento de orgulho pela autoria da transformação daqueles objetos outrora desprezados, fenômeno associado ao prazer social.

Figura 6: Objetos transformados: tampo de mesa revestida de tampas; cooler e frente da geladeira revestidos de rótulos (usado com a permissão de A.P. e R.C.).
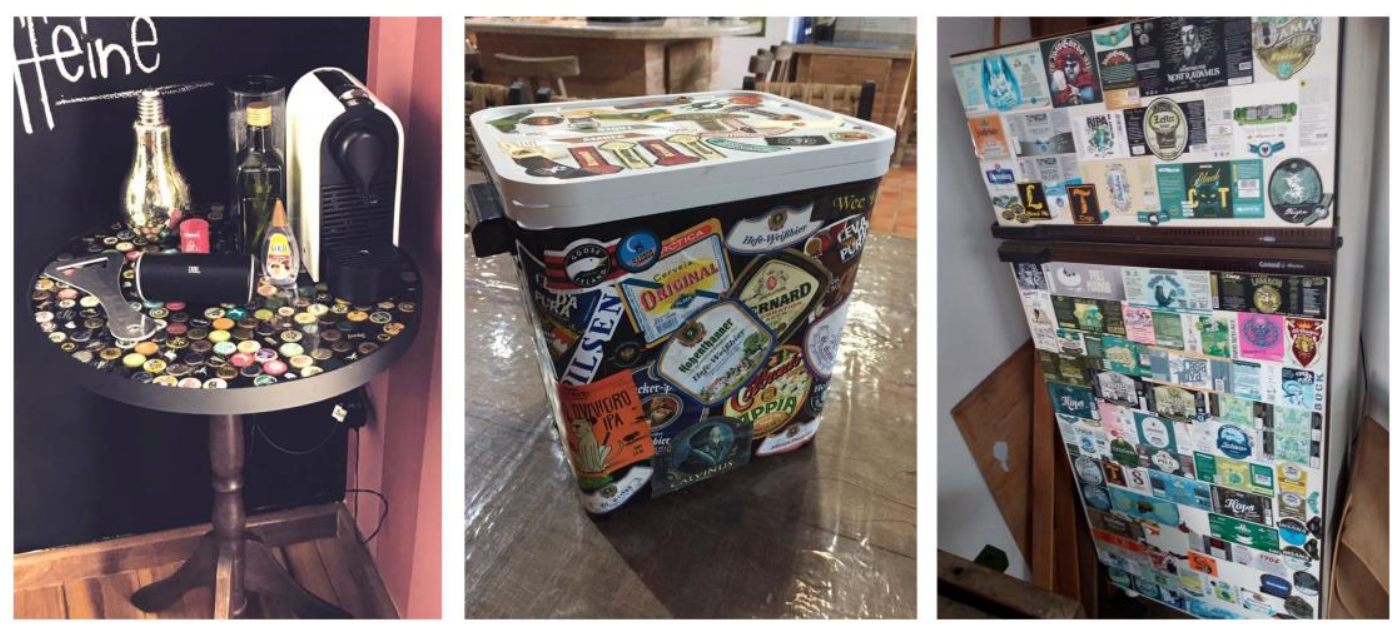

\section{Enfeite útil}

A última categoria foi intitulada "enfeite útil" a partir do depoimento do entrevistado que assim denominou a nova função para a garrafa transformada em candelabro. Engloba objetos considerados tanto úteis quanto decorativos, à medida em que foram transformados em algo que apresenta uma função prática definida, como um vaso ou candelabro, ao mesmo tempo em que mantém a função estética de enfeitar o ambiente.

Relacionam-se com o prazer fisiológico, mas também com o prazer social pois, assim como

Anais do 9 Congresso Internacional de Design da Informação | CIDI 2019 
na categoria anterior, tem a ver com o orgulho em transformar uma embalagem em algo novo, bonito e útil.

Figura 7: Garrafa-candelabro enfeita o aparador na varanda; garrafa-vaso exibe flores secas no balcão da cozinha; latas-vasos de suculentas enfeitam o muro (usado com a permissão de K.L.).
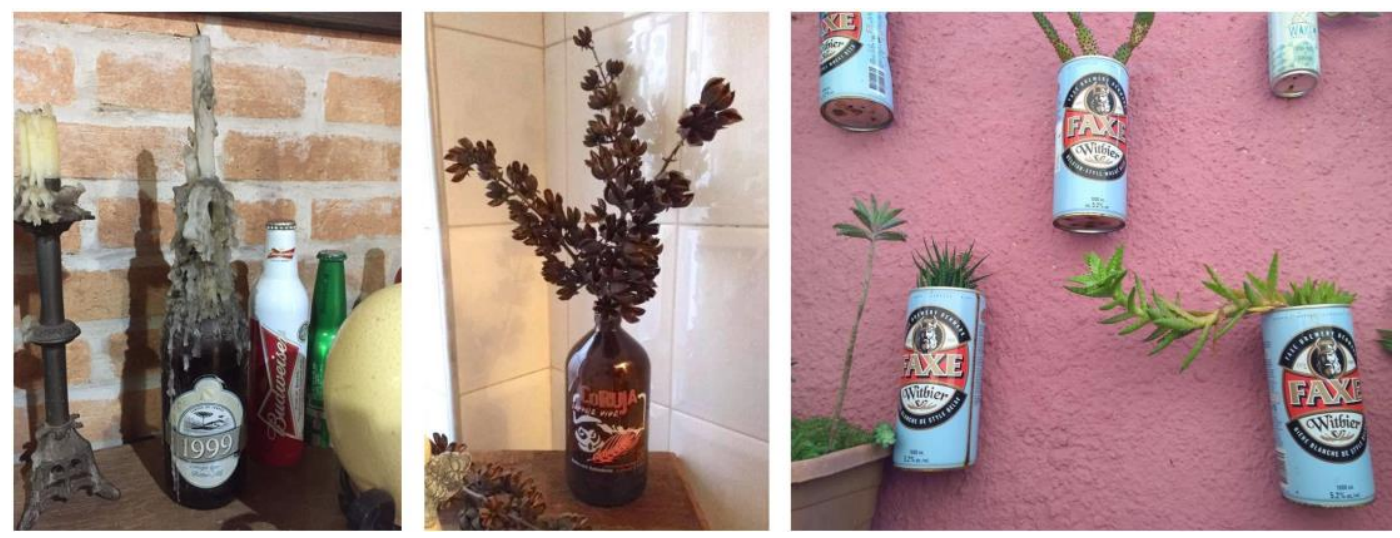

\section{Conclusões}

Historicamente as embalagens têm atuado no ponto de venda como agentes de marketing a fim de influenciar o consumidor no momento da compra, tendo em vista diferenciar os produtos frente à concorrência. Do ponto de vista do design da informação, deve ser capaz de transmitir de forma eficiente e eficaz uma série de informações que faça sentido para as pessoas.

Após a aquisição dos produtos, as embalagens continuam a atuar e buscam promover boas e prazerosas experiências de consumo, de modo a estabelecer um relacionamento duradouro entre consumidores e marcas. Entretanto, como nos lembra Baudrillard (2004, p.94), todo objeto tem duas funções, 'uma que é a de ser utilizado, a outra a de ser possuído'.

O que o estudo revela é que as embalagens e objetos relacionados a elas que servem como ponto de contato com a marca, tais como as bolachas, também se prestam para ser possuídos, para enfeitar a casa, rememorar lugares e experiências vividas, despertar emoções, promover estórias pessoais e únicas, e a própria noção de identidade destas pessoas.

Embalagens monouso, a priori artefatos efêmeros, tiveram sua vida estendida motivada por relações de ordem afetiva, contrariando sua natureza passageira, ao permanecerem no tempo.

Promovem narrativas sobre estilos de cerveja, nomenclaturas específicas, curiosidades a respeito de um saber-fazer que ganhou popularidade nos últimos anos, o do "cervejeiro artesanal doméstico". Compõem um tipo de conjunto cujo interesse em aumentá-lo age como motivador de novas conquistas, exatamente por sua incompletude eterna, mantendo acesa a chama da posse.

Os fatores observados como motivadores do fenômeno da permanência relacionam-se com atributos estéticos, mas principalmente, pelos significados destes objetos e o que representam uma vez que, além de decorativos e eventualmente úteis, eles se apresentam como objetos afetivos, vinculados a emoções como diversão, satisfação, prazer, interesse, alegria, admiração, felicidade, orgulho ou mesmo ciúmes, tensão e culpa.

Encontra-se aqui o potencial para a otimização da vida de embalagens por meio de projeto, considerando que estas podem adquirir valor com o tempo de uso por cercarem-se com 'uma esfera de afetividade e de atenções', conforme sugerem Manzini e Vezzoli (2011, p.187).

Finalmente, é importante ressaltar que as relações aqui estabelecidas com os objetos estudados ocorreram por meio de sua materialidade e seus elementos constitutivos, na forma de rótulos, letterings, ilustrações, cores, vidros, formatos e fechos, em outras palavras, seu design, agente promotor das experiências emocionais desejadas pelas pessoas.

Anais do 9ำ Congresso Internacional de Design da Informação | CIDI 2019 
Ardinghi, M.B. \& Bertoldi, C.A. | O fenômeno da permanência de artefatos comunicacionais efêmeros do universo da cerveja sob a ótica do design emocional

\section{Referências}

Baudrillard, J. (2004). O Sistema dos Objetos. 5. ed. São Paulo: Perspectiva, 2004.

Csikszentmihalyi, M. \& Rochberg, E. (1981). The meaning of things: domestic symbols and the self. Cambridge: Cambridge University Press.

Damazio, V. (2005). Artefatos de Memória da Vida Cotidiana: um olhar interdisciplinar sobre as coisas que fazem bem lembrar. Tese (Doutorado). Rio de Janeiro: UERJ

Horn, R. E. (1999). Information design: Emergence of a new profession. Information design. Em Jacobson, R. E. \& Jacobson, R. (Eds.). Information design. (pp 15-34). Cambridge, MA: MIT Press.

Jordan, P. (2000). Designing pleasurable products. London, Taylor \& Francis.

Lazarus, R.S. (1991). Emotion and adaptation. Oxford, Oxford University Press.

Löbach, B. (2001). Design industrial: bases para a configuração dos produtos industriais. São Paulo: Blucher.

Manzini, E.; Vezzoli, C. (2011). O desenvolvimento de produtos sustentáveis. São Paulo: Ed. USP.

Mestriner, F. (2002). Design de embalagem: curso básico. Pearson Makron Books.

Negrão, C.; Camargo, E. (2008). Design de embalagem: do marketing à produção. São Paulo: Novatec.

Norman, D. A. (2008) Design emocional: por que adoramos (ou detestamos) os objetos do diaa-dia. Rio de Janeiro: Rocco.

Portugal, C. (2010). Complex questions about information and interaction Design/ Questões complexas do design da informação e de interação. Brazilian Journal of Information Design, 7(2), pp 1-8.

Scherer, K. R. (2005). What are emotions? And how can they be measured? Social Science Information, v. 44, n. 4, pp. 695-729.

Stewart, BILL. (2010). Estratégias de design para embalagens. São Paulo: Blucher.

Tonetto, L. M.; Da Costa, F. C. X. (2011). Design Emocional: conceitos, abordagens e perspectivas de pesquisa. Strategic Design Research Journal, v. 4, n. 3. pp.132-140.

\section{Sobre as autoras}

Maria Beatriz Ardinghi, Mestra em Design e Arquitetura, Doutoranda em Design, FAU USP, Brasil <beatrizardinghi@gmail.com>

Cristiane Aun Bertoldi, Doutora em Arquitetura e Urbanismo, FAU USP, Brasil <craun@usp.br> 